\title{
Ergonomics Evaluation of Single Row Power Weeder for Rice
}

\author{
Aditya Sirmour $^{1 *}$, Ajay Verma ${ }^{1}$, Mukesh Pandey ${ }^{2}$ and Animesh Chandrawanshi ${ }^{1}$ \\ ${ }^{1}$ Department of Farm Machinery and Power Engineering, Faculty of Agricultural \\ Engineering, I.G.K.V (Raipur), India \\ ${ }^{2}$ Department of Agronomy, Faculty of Agricultural Engineering, I.G.K.V (Raipur), India
}

*Corresponding author

\section{A B S T R A C T}

\section{Keywords}

Ergonomics, Power weeder, Rice,

Mechanical weed control

Article Info

Accepted:

06 December 2017

Available Online:

10 January 2018
Weed control is one of the most difficult tasks on an agricultural farm. Mechanical weed control not only uproots the weeds between the crop rows but also keeps the soil surface loose, ensuring better soil aeration and water intake capacity. The developed weeder should have the following features: $2.0 \mathrm{hp}, 2$-stroke petrol engine. It is compact light low weight equipment, self-propelled with durable floating system. It is centrally driven with worm gear box for transmission. The working width of the developed machine could be adjusted between $140 \mathrm{~mm}$ to $250 \mathrm{~mm}$. It is equipped with rotating blades with $176 \mathrm{rpm}$ and is centrally driven. The cardiac cost involved in the operation of power paddy weeder was found out and the mean working heart rate value of the subject was 108 beats min-1. The energy expended during operation of a power paddy weeder was $19.50 \mathrm{~kJ} \mathrm{~min}^{-1}$. The oxygen uptake in terms of VO2 max was $46 \%$ which was above the acceptable limit of $35 \%$ of $\mathrm{VO} 2$ max. Mean overall discomfort rating on a 10 point visual analogue discomfort scale (0- no discomfort, 10- extreme discomfort) was 3.0 and scaled as "light discomfort".

\section{Introduction}

Weeding out of unwanted plants is a very difficult task in Indian agriculture manually as well as using bullock operated equipment's and consumes $15 \%$ of total energy spent in crop production. If there is a delay and negligence in weeding operation crop yield is affected up to 30 to $60 \%$ (Singh, 1988). Weeds waste excessive proportions of farmers' time, thereby acting as a brake on development. Weeding operation is performed generally manually which involves highly labour input and time consuming. 16-42\% reduction in crop yield is estimated due to weed alone and involves one-third of total cost of cultivation (Rangasamy et al., 1993). Mechanical weed control reduces the drudgery involved in uprooting of the weeds. The engine-powered implements have a strong, direct impact over operational drudgery, saving its operator (or more than one) from an otherwise very tiring process.

An ergonomic dimension corresponds best to the orientation of the designed machine which are worked in different positions and postures should be different as per the region to meet 
the requirement of soil type, crop grown, anthropometric measurement's. Hence the effort has been made to develop a weeder to meets the demand of the farmers and achieve the better efficiency, human comfort and safety. The performance of any machine especially manually operated ones could be considerably improved if ergonomic aspects are given due weightage (Gite, 1993). Measurement of physiological parameters of the operator are also important from the safety point of view because whenever the physical capacity of a person is exceeded, it is bound to cause considerable fatigue and large reduction in the alertness of the person making the operation unsafe.

\section{Materials and Methods}

Development of single row active power weeder (rice) for weeding is designed with the ergonomics point of view such that agriculture workers can work effectively with less drudgery. The various design parameters have consider for developing machine. Adjustability to change the width of working, it varied from $140 \mathrm{~mm}$ to $240 \mathrm{~mm}$. light weight be developed to lessen fatigue/workload on the operator and easy to operate, low maintenance thereby facilitating them to walk comfortably behind the weeder.

It is best suited for rice crop weeding having row spacing between $170 \mathrm{~mm}$ to $240 \mathrm{~mm}$. The developed weeder should have the following features: $2.0 \mathrm{hp}, 2$-stroke petrol engine. It is compact light low weight equipment, selfpropelled with durable floating system. It is centrally driven with worm gear box for transmission. The working width of the developed machine could be adjusted between $140 \mathrm{~mm}$ to $250 \mathrm{~mm}$. It is equipped with rotating blades with $176 \mathrm{rpm}$. Due to compactness and low weight it is easily manoeuvrable. The technical specifications of the power tiller are given in Table 1.

\section{Design consideration}

A manually operated power weeder was designed for weeding of mechanical and manual transplanting of rice. From the design point of view- power source (engine), cutting blades shaft were the important components of single row power weeder for rice. Conceptual design of power weeder was prepared with Solid Works software it is shown in Fig.1.

\section{Ergonomic evaluation}

The subjects were in the age group of 26 to 42 years. Nineteen anthropometric measurements were taken, which were considered useful for designing of power weeder. Table 2 shows the body dimensions.

\section{Field layout experiments}

The experiment was conducted in farmer's field in different district of Chhattisgarh. Power weeder is a manually operated implement and designed to work in between the rows of 14-25 cm spacing in wet lands. All the operators were equally trained in the operation of the power paddy weeder. The subjects were given information about the experimental requirements so as to enlist their full cooperation. The physiological parameter was measured and recorded using stethoscope, pulse oximeter, B.P monitor machine, BMI machine and fitness band. Each trial started with taking five minutes data for physiological responses of the subjects while resting on a stool under shade.

\section{Data Analysis}

The stabilized values of heart rate for each subject during operation after every $7^{\text {th }}$ to $15^{\text {th }}$ min as per operator condition were used to calculate the mean value for power paddy weeder. From the mean values of heart rate (HR) observed during the trials, the 
corresponding values of oxygen consumption rate $\left(\mathrm{VO}_{2}\right)$ of the subjects were predicted from the calibration curves of the subjects. The energy costs of the operations were computed by multiplying the value of oxygen consumption (mean of the values of three subjects) by the calorific value of oxygen as $20.88 \mathrm{~kJ} \mathrm{lit}^{-1}$.

\section{Body part discomfort score (BPDS)}

The body part discomfort score of each subject was the rating multiplied by the number of body parts corresponding to each category. The subjects were asked to locate the body parts with respect to degree of discomfort in the order as extremely heavy, very heavy, moderately heavy, heavy, light and very light. The body part discomfort was determined by the following formula (Corlett and Bishop, 1976):

$\mathrm{BPDS}=\mathrm{S} \mathrm{X}_{\mathrm{i}} * \mathrm{~S}(3.40)$

Where,

BPDS $=$ Body parts discomfort score

$X_{\mathrm{i}}=$ Number ofbody parts

$\mathrm{S}=$ Discomfort score (6 to 1$)$

\section{Results and Discussion}

Physiological evaluation

\section{Heart rate}

Initially heart rate was different for each different group ranging between 60 to 66 beats per min. For a particular workload the heart rate showed a sudden increase in starting periods of work and then established throughout the work. After the completion of the work, heart rate decreases drastically. Average heart rate of different age groups after the commencement of weeding operation was found as 109, 116, 111 and 114 beats /min. The detailed observed data of heart rate, of a particular subject with time duration shown in fig 4.

\section{Energy cost of operation}

The average working heart rate of the operator was 109.55 beats $\mathrm{min}^{-1}$ and the corresponding value of oxygen consumption rate was 0.571 $\min ^{-1}$. The corresponding energy expenditure was $12.60 \mathrm{kJmin}^{-1}$. Based on the mean energy expenditure, the operation was graded as "Moderately Heavy"

Fig.1 Conceptual design of power weeder prepared with Solid Works software

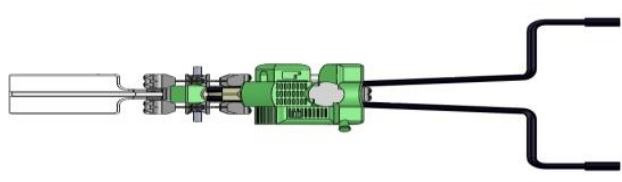

TOP VIEW

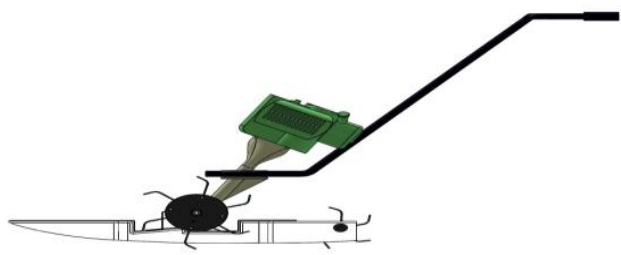

FRONT VIEW

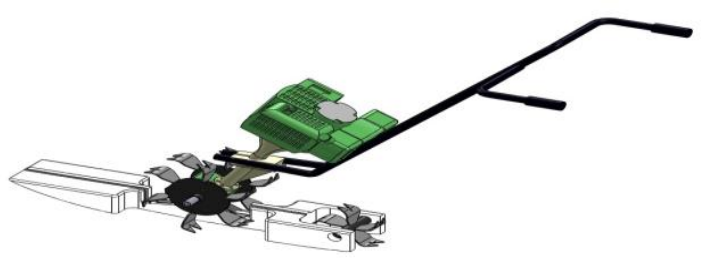

ISOMATRIC VIEW

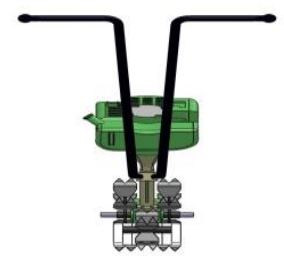

SIDE VIEW 
Fig.2 Heart Rate caliberation during operation with the help of fitness band

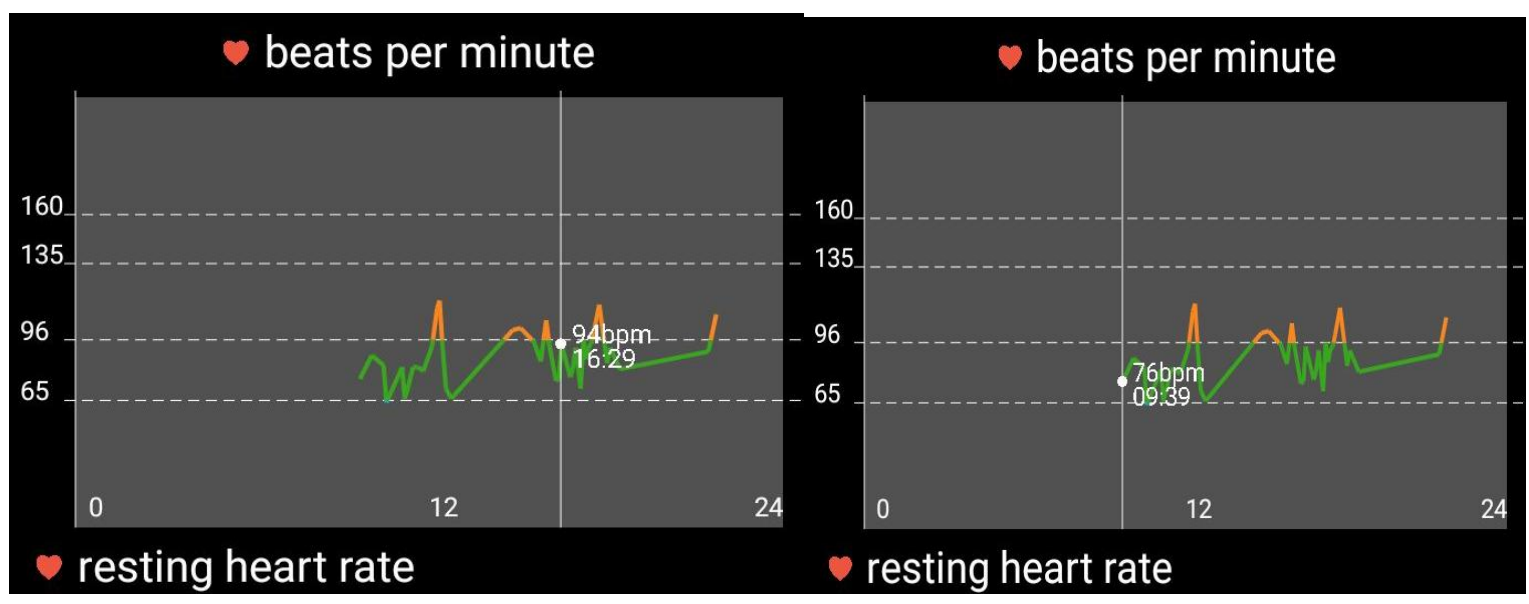

Fig.3 Field testing of power weeder at Research Farm IGKV, Raipur
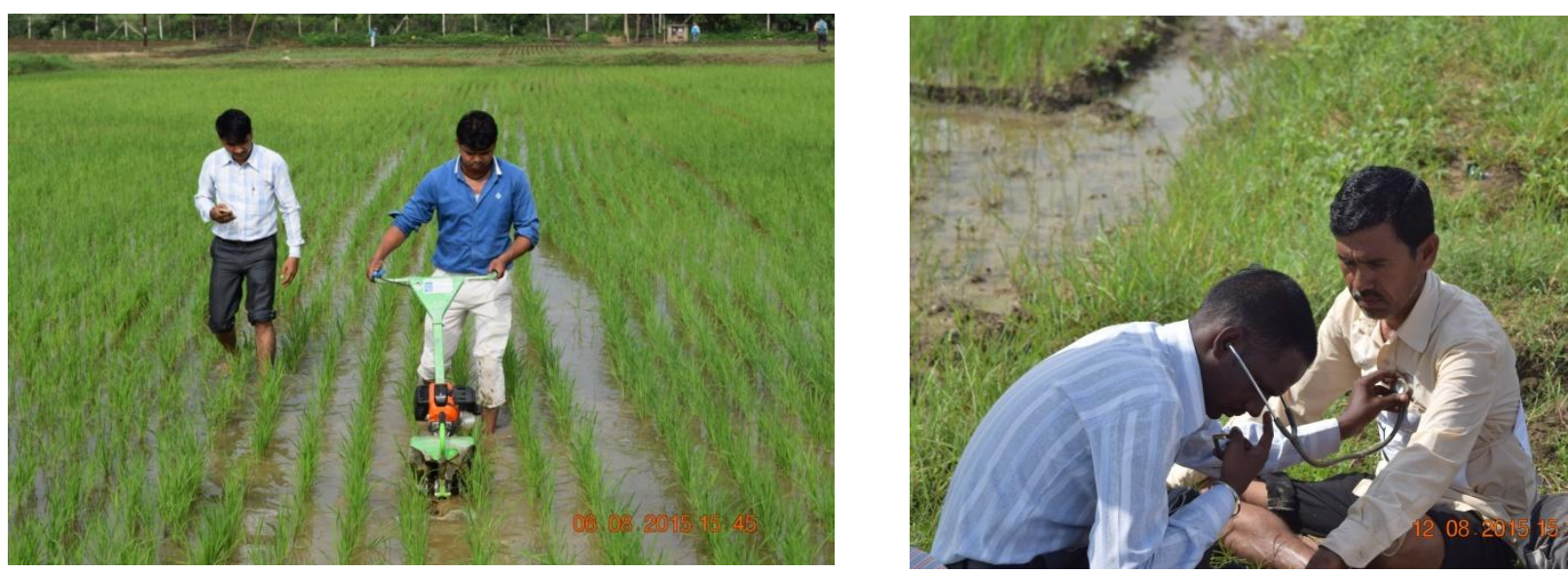

Fig.4 Stress stabilization for power weeder

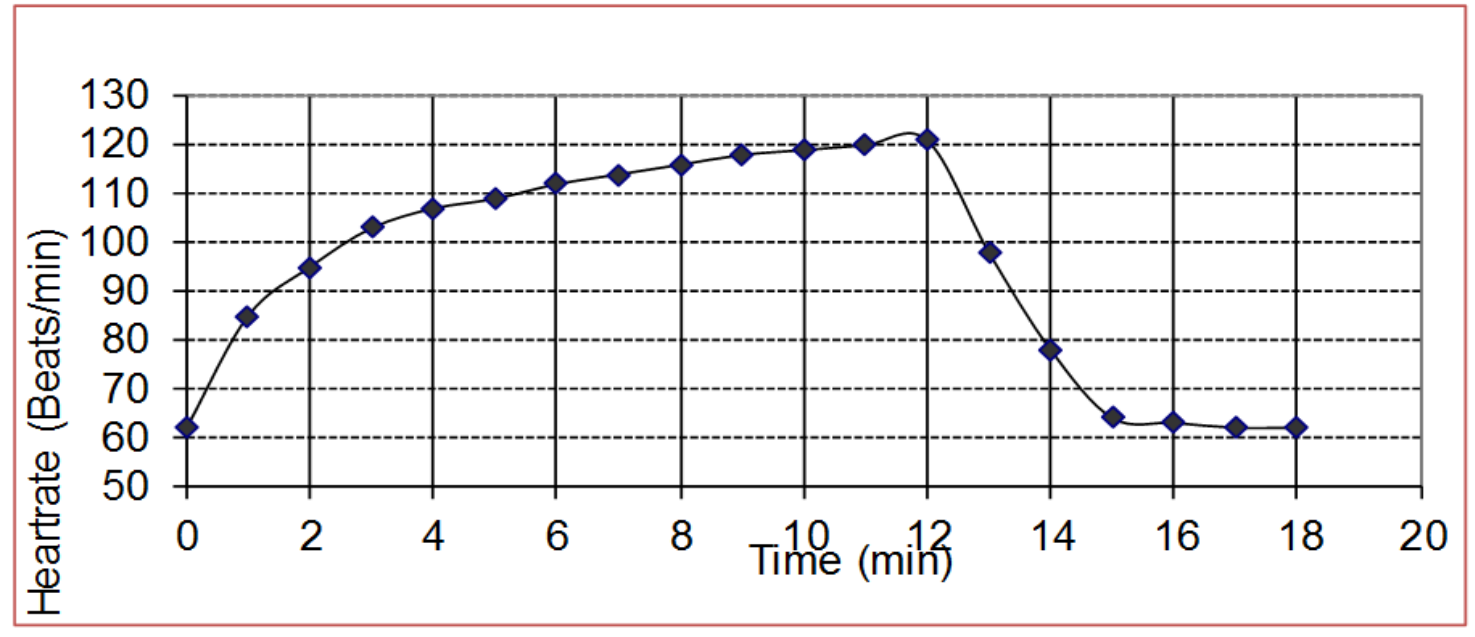


Table.1 Technical specification of power weeder

\begin{tabular}{|l|r|}
\hline Specification & Value \\
\hline Number of cylinder & 1 \\
\hline Engine maximum power at 6000 rpm & $2 \mathrm{hp}$ \\
\hline Weeding width & $140 \mathrm{~mm}$ to $250 \mathrm{~mm}$ \\
\hline No. of Blades & 8 \\
\hline Rotavator speed & $176 \mathrm{rpm}$ \\
\hline Overall dimension (LxWxH) & $890 \times 325 \times 580 \mathrm{~mm}$ \\
\hline Total weight & $14.5 \mathrm{~kg}$ \\
\hline
\end{tabular}

Table.2 Selected Body Dimensions of Subject's taken for study

\begin{tabular}{|c|c|c|c|c|c|c|}
\hline \multirow[t]{2}{*}{ Sl. No. } & \multirow[t]{2}{*}{ Dimensional Element (mm) } & \multicolumn{5}{|c|}{ Subjects } \\
\hline & & 1 & 2 & 3 & 4 & 5 \\
\hline 1 & Height & 1720 & 1650 & 1670 & 1590 & 1640 \\
\hline 2 & Eye Height Standing & 1610 & 1535 & 1542 & 1495 & 1550 \\
\hline 3 & Eye Height Sitting & 1214 & 1189 & 1196 & 1059 & 1170 \\
\hline 4 & Sitting height & 910 & 900 & 904 & 890 & 830 \\
\hline 5 & Shoulder Breadth & 425 & 410 & 414 & 395 & 405 \\
\hline 6 & Chest Depth & 220 & 217 & 218 & 205 & 220 \\
\hline 7 & Hip Breadth; standing & 315 & 309 & 311 & 315 & 305 \\
\hline 8 & Hip Breadth; Sitting & 580 & 570 & 572 & 561 & 570 \\
\hline 9 & Shoulder Elbow & 397 & 385 & 389 & 365 & 375 \\
\hline 10 & Forearm - hand & 421 & 419 & 419 & 388 & 422 \\
\hline 11 & Arm reach & 692 & 688 & 688 & 652 & 685 \\
\hline 12 & Elbow height: sitting & 195 & 187 & 188 & 172 & 170 \\
\hline 13 & Buttock knee & 562 & 559 & 560 & 530 & 552 \\
\hline 14 & Seat length & 467 & 460 & 461 & 448 & 458 \\
\hline 15 & Knee height: sitting & 521 & 520 & 524 & 503 & 523 \\
\hline 16 & Seat height & 439 & 425 & 426 & 407 & 422 \\
\hline 17 & Foot length & 259 & 250 & 252 & 239 & 248 \\
\hline 18 & Foot breath & 874 & 900 & 892 & 860 & 875 \\
\hline 19 & Age (years) & 26 & 30 & 35 & 42 & 24 \\
\hline
\end{tabular}

(Measuring unit: $\mathrm{mm}$ unless otherwise specified)

\section{Body part discomfort score (BPDS)}

The majority of discomfort was experienced in the left shoulder, right shoulder, left wrist, right wrist, left thigh and right thigh region for all the subjects during weeding and the body part discomfort score of subjects during weeding with power rice weeder was 24.12.

\section{Work rest cycle}

Rest pause was calculated, as all the subjects 
operated continuously for the 25 min period and it was found that $7 \mathrm{~min}$ rest could be provided to operator who was engaged in operating the equipment.

The performance of rice weeder was found excellently on wet condition and is easy to operate. The developed weeder could work upto the depth of $4-8 \mathrm{~cm}$ with the field capacity of $33.33 \mathrm{~h} / \mathrm{ha}$. Fuel consumption of the weeder was $2 \mathrm{l} / \mathrm{h}$. The operating cost of the rotary rice weeder was Rs.980/ha compared to Rs. 2300/ha for manual weeding.

\section{Acknowledgements}

The authors are thankful to TATA Trust, Southern Agro. Pvt. Ltd. for providing facilities to carry out this work. Thanks also to Mr Pramod and Mr Pandey for extending help during the course of investigation.

\section{References}

Corlett, E.N. and Bishop, R.P. 1976. A technique for assessing postural discomfort. Ergonomics, 19(2), 175182.

Gite, L.P. and Yadav, B.G. 1993.Ergonomic consideration in the design of mechanical weeders. Proceedings on Design Course of Agricultural Machines. Central Institute of Agricultural Engineering, Bhopal.

Rangasamy, K., Balasubramanian, $\mathrm{M}$ and K.R. Swaminathan. 1993. Evaluation of power weeder performance. Agricultural Mechanisation in Asia, Africa and Latin America, 24(4):16-18.

Singh, G. 1988. Development and fabrication techniques of improved grubber. Agricultural Mechanisation in Asia, Africa and Latin America, 2:42-46.

\section{How to cite this article:}

Aditya Sirmour, Ajay Verma, Mukesh Pandey and Animesh Chandrawanshi. 2018. Ergonomics Evaluation of Single Row Power Weeder for Rice. Int.J.Curr.Microbiol.App.Sci. 7(01): 681-686. doi: https://doi.org/10.20546/ijcmas.2018.701.083 